\title{
ELECTROCHEMICAL DEPOSITION AND DISSOLUTION OF THALLIUM OXIDE (III)
}

\author{
GULZIYA A. SEILKHANOVA ${ }^{a}$ *, ANDREY P. KURBATOV ${ }^{a}$, \\ YENLIK ZH. USSIPBEKOVA ${ }^{a}$, ANDREY V. BEREZOVSKIYa, \\ MICHAEL K. NAYRYZBAEV ${ }^{a}$
}

\begin{abstract}
The regularities of precipitation and dissolution of thallium (III) oxide were studied by using cyclic and linear voltammetry. It is established that at $1.5 \mathrm{~V}$ potential, a peak corresponding to the process of oxidation of monovalent to trivalent thallium is observed, according to: $\mathrm{Tl}^{+} \rightarrow \mathrm{Tl}^{3+}+2 \mathrm{e}^{-}$.

Two peaks are observed in the cathode region, at $0.65 \mathrm{~V}$ and $-0.17 \mathrm{~V}$ potential values. At $\mathrm{E}=-0.17 \mathrm{~V}$, the thallium oxide $\mathrm{Tl}_{2} \mathrm{O}_{3}$ dissolves, as at $\mathrm{E}=$ $0.65 \mathrm{~V}$, the intermediate products of the hydrolysis of trivalent thallium $\left(\mathrm{TI}(\mathrm{OH})^{2+}, \mathrm{TI}(\mathrm{OH})^{2+}\right)$ are probably recovered. It was found that with increase of solution $\mathrm{pH}$, the dissolution processes of thallium oxide intensified, while the optimum $\mathrm{pH}$ value was 11 , also activation energy of the electrodeposition of thallium(III) oxide were calculated.
\end{abstract}

Keywords: thallium, thallium(III) oxide, electrolysis, voltammetry, precipitation, dissolution/solution.

\section{INTRODUCTION}

Today it is difficult to call the field of technology that would not use rare metals, their alloys and various compounds. Due to its physical-chemical properties, thallium, as well as its compounds of high purity, is widely used in many fields of science and technology. In particular, metal thallium is used to obtain bearing and low-melting alloys, in semiconductors, as a source of $\beta$ radiation it is used in radioisotope devices [1-3]. Alloys containing thallium have increased resistance, inertness with respect to acids, low melting point.

\footnotetext{
${ }^{a}$ Al-Farabi Kazakh National University, Faculty of Chemstry and Chemical Technology 71 AlFarabi av., 050040 Almaty, Kazakhstan,

*Corresponding authorg_seilkhanova@mail.ru
} 
It is known that thallium is used as a catalyst in the obtaining of special alloys, optical lenses, jewelry, and the creation of low temperature thermometers. Thallium compounds are also used as medicines against rodents and insecticides [4-6]. It should be noted that the high toxicity and volatility of thallium compounds are not fundamental obstacles for the use of compositions based on it in engineering. In modern production and technology, the obtaining and use of particularly pure and ultrapure substances play an important role. Obtaining thallium of high purity is a complex technological task requiring the use of complex technological schemes, including both physical and chemical methods of purification. To determine the amount of impurities or the detection of traces of foreign matter in various materials, it is possible to successfully apply electrochemical methods, in particular, the method of electrochemical refining [7]. Therefore, the physical-chemical study of processes in the refining of thallium is very relevant.

This is characterized by the simplicity of appliance design and the possibility of effectively conducting the process at medium temperatures and pressures, yet with high performances. However, it is quite difficult to obtain high-purity thallium by electrolysis due to the similarity of chemical properties and very close position of electrode potentials of thallium and other metal impurities. The authors demonstrated previously [8-12] the principles of possible electrochemical thallium refining through the dissolution stage of anodically-deposited thallium(III) oxide.

As a result, this work aimed the establishing the regularities during precipitation and dissolution of thallium(III) oxide, for the selective electrochemical deposition of a rare metal.

\section{RESULTS AND DISCUSSION}

In order to optimize the purification process of rough thallium, the studies were carried out in a volumetric electrolysis cell with a potential of 1.5 V. A glassy carbon plate was used as cathode, platinum served as anode, and a silver chloride electrode as reference, respectively. In addition to the deposition of thallium $\left(\mathrm{TI}^{+}+1 \mathrm{e}^{-} \rightarrow \mathrm{TI}^{0}\right)$ on the cathode, the platinum plate at the anode was covered at $\mathrm{pH}>2$ with a dark brown precipitate that corresponds to the trivalent thallium oxide [13]. Thus, the following process takes place on the anode:

$$
2 \mathrm{TI}^{+}+3 \mathrm{H}_{2} \mathrm{O}=\mathrm{TI}_{2} \mathrm{O}_{3}+6 \mathrm{H}^{+}+4 \mathrm{e}^{-}
$$


Higher impurity contents (such as $\mathrm{Pb}, \mathrm{Cu}, \mathrm{Cd}$ ) are observed in the cathode sediments, because of their close or more positive electrode potentials [8]. The anode's precipitate, thallium oxide $\mathrm{Tl}_{2} \mathrm{O}_{3}$, is purer. The only impurity which precipitates along with thallium oxide, due to the close $\mathrm{pH}$ of hydrate formation, is iron hydroxide. The purity of the anode sediment is $99.6 \%$. The fact of formation of purer thallium(III) oxide on the anode can be used for refining the rough metal. Results in the literature [14] indicate the possibility of selective precipitation of thallium by using an anode precipitate $-\mathrm{Tl}_{2} \mathrm{O}_{3}$, while the purity of rare metal is $99.98 \%$.

To establish the regularities of electrochemical deposition and dissolution of $\mathrm{Tl}_{2} \mathrm{O}_{3}$, cyclic polarization curves were taken at different scanning rates, electrolyte stirring rates and temperatures.

Figure 1 shows cyclic volt-ampere curves at different scanning speeds. In the anode region, where the potential equals $1.5 \mathrm{~V}$, a peak corresponding to the process of oxidation of monovalent to trivalent thallium $\left(\mathrm{TI}^{+}-2 \mathrm{e}^{-}=\mathrm{Tl}^{3+}\right)$ is observed.

After that, the oxide formation takes place according to the following scheme:

$$
\mathrm{TI}^{3+} \leftrightarrow \mathrm{TIOH}^{2+} \leftrightarrow \mathrm{TI}(\mathrm{OH})_{2}{ }^{+} \leftrightarrow \mathrm{TI}(\mathrm{OH})_{3} \leftrightarrow \mathrm{Tl}_{2} \mathrm{O}_{3}
$$

In the cathode region, two peaks are observed with potentials equaling $0.65 \mathrm{~V}$ and $-0.17 \mathrm{~V}$, respectively. At $-0.17 \mathrm{~V}, \mathrm{Tl}_{2} \mathrm{O}_{3}$ dissolves according to the reaction:

$$
\mathrm{Tl}_{2} \mathrm{O}_{3}+3 \mathrm{H}_{2} \mathrm{O}+4 \mathrm{e}^{-}=2 \mathrm{TI}^{+}+6 \mathrm{OH}^{-}
$$

At $0.65 \mathrm{~V}$ potential, the intermediate products of the hydrolysis of trivalent thallium $\left(\mathrm{TIOH}^{2+}, \mathrm{TI}(\mathrm{OH})_{2}{ }^{+}\right)$are probably recovered. With a decrease scanning speeds of the amount of electricity spent on the reduction process, presumably intermediate hydrolysis products, quantitatively goes into the amount of electricity spent to dissolve thallium oxide.

This indicates that the intermediate products of hydrolysis are not very stable and eventually transform into $\mathrm{Tl}_{2} \mathrm{O}_{3}$. To confirm this fact, $\mathrm{Tl}_{2} \mathrm{O}_{3}$ was precipitated in potentiostatic mode, at $\mathrm{E}=1.5 \mathrm{~V}$, for 30 seconds. The cathode polarization curves were registered immediately after precipitation, and furthermore after every 5, 10, 15 seconds. These are presented in Fig. 2. 


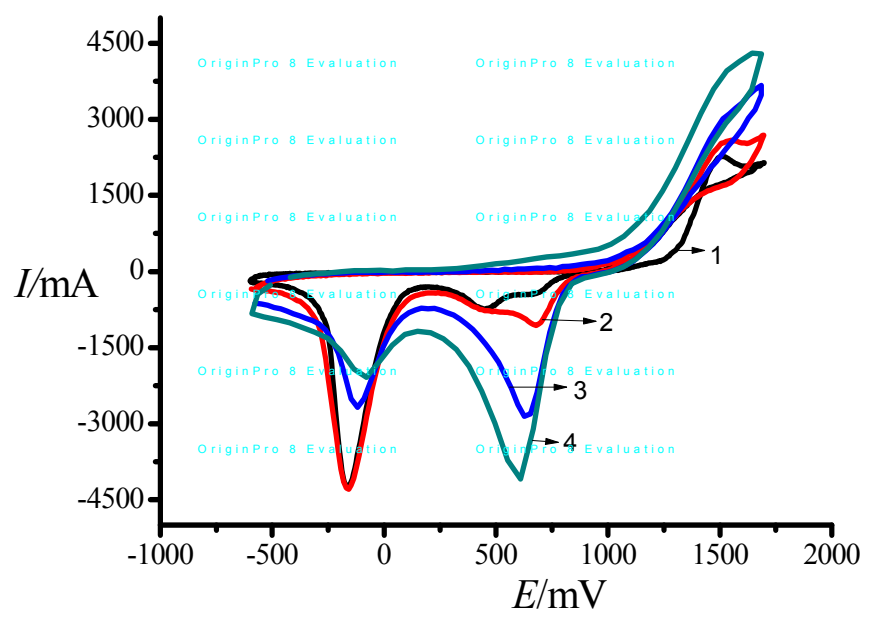

$1-10 \mathrm{mV} / \mathrm{s} ; 2-20 \mathrm{mV} / \mathrm{s} ; 3-50 \mathrm{mV} / \mathrm{s} ; 4-100 \mathrm{mV} / \mathrm{s}$.

Figure 1. Cyclic polarization curves of thallium on a glassy carbon electrode $\left(\mathrm{c}=10^{-2} \mathrm{M}\right)$ at different scanning speeds

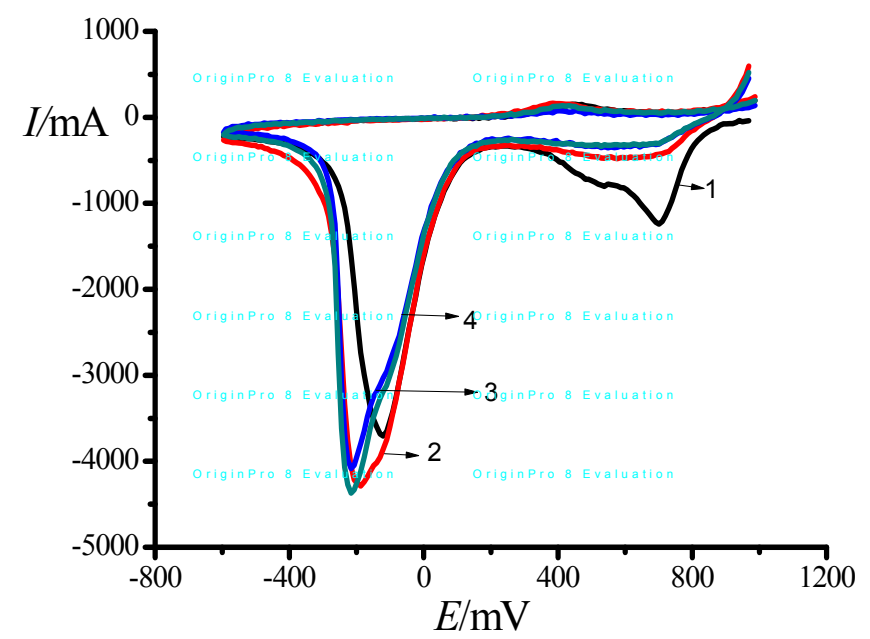

1-0 s; 2-5 s; 3-10 s; 4-15 s.

Figure 2. Cathode polarization curves on glass carbon electrode at different holding times, after precipitation of thallium oxide, at a potential of $1.5 \mathrm{~V}$ 
Table 1. Amount of electricity, $\%$, spent on cathodic processes at potentials of 0.65 and $-0.17 \mathrm{~V}$, respectively.

\begin{tabular}{|l|l|l|l|l|}
\hline $\mathrm{E}(\mathrm{V})$ & $\begin{array}{c}\text { Amount of } \\
\text { electricity, \%, } \\
(0 \mathrm{sec})\end{array}$ & $\begin{array}{c}\text { Amount of } \\
\text { electricity, \% } \\
(5 \mathrm{sec})\end{array}$ & $\begin{array}{c}\text { Amount of } \\
\text { electricity, \% } \\
(10 \mathrm{sec})\end{array}$ & $\begin{array}{c}\text { Amount of } \\
\text { electricity, \% } \\
(15 \mathrm{sec})\end{array}$ \\
\hline 0.65 & $32.1 \pm 0.28$ & $11.9 \pm 0.13$ & $9.5 \pm 0.11$ & $4.8 \pm 0.06$ \\
\hline-0.17 & $67.9 \pm 0.70$ & $88.1 \pm 0.91$ & $91.5 \pm 0.94$ & $95.2 \pm 0.97$ \\
\hline
\end{tabular}

As can be seen from figure 2 and table 1, over time of the amount of electricity spent on the reduction process, presumably intermediate hydrolysis products, quantitatively goes into the amount of electricity spent to dissolve thallium oxide, which gives the possibility of complete electrochemical dissolution of the oxide when potential equal to $-0.17 \mathrm{~V}$.

In order to prove the fact that thallium oxide dissolves with the formation of monovalent thallium, $\mathrm{Tl}_{2} \mathrm{O}_{3}$ was precipitated in potentiostatic mode $(E=1.5 \mathrm{~V})$ during the 5 minutes. Further, cathode polarization curves were registered to study the cathode peaks (Fig. 3). As can be seen from Fig. 3 , two peaks are observed on the graph, indicating a two-stage dissolution mechanism of $\mathrm{Tl}_{2} \mathrm{O}_{3}$. At $\mathrm{E}=-0.25 \mathrm{~V}$, thallium(III) oxide is recovered in a monovalent state:

$$
\mathrm{Tl}_{2} \mathrm{O}_{3}+3 \mathrm{H}_{2} \mathrm{O}+4 \mathrm{e}^{-}=2 \mathrm{Tl}^{+}+6 \mathrm{OH}^{-}
$$

Further, at $\mathrm{E}=-0.86 \mathrm{~V}$, the recovery of the monovalent to metallic thallium takes place [15]: $\mathrm{TI}^{+}+\mathrm{e}^{-}=\mathrm{TI}^{0}$

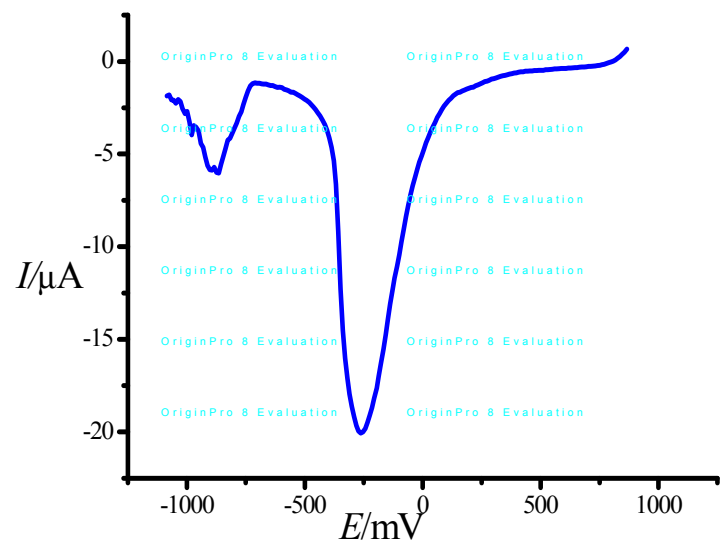

Figure 3. Cathode polarization curve on glass carbon electrode of deposited thallium oxide after precipitation during 5 minutes. 
The dependence of the magnitude of the thallium peak amperage on the potential sweep speed is analyzed. As can be seen from Figure 4, an increase of the sweeping speed increases the amperage's peak. This may indicate a diffusion mode of the electrode process, because with an increase of the sweep rate, a linear dependence of the amperage density in the anode processes on the square root of the sweep speed is observed. In cathode processes, it is impossible to draw unambiguous conclusions through this parameter, because the processes of recovering intermediate products of trivalent thallium hydrolysis interfere with voltammograms.

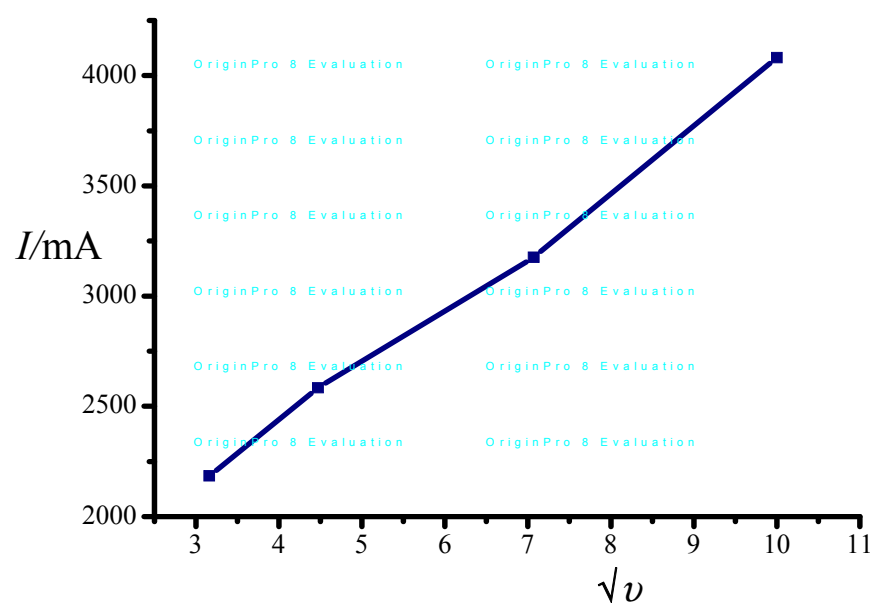

Figure 4. The amperage density dependence of the anode peaks on $\sqrt{ } \mathrm{U}$, where $u$ is the sweep speed $\left(\mathrm{Tl}_{2} \mathrm{SO}_{4}, \mathrm{C}=10^{-2} \mathrm{~mole} / \mathrm{L}\right)$

In order to determine the nature of the limiting stage of the process of precipitation and dissolution of $\mathrm{Tl}_{2} \mathrm{O}_{3}$, cyclic polarization curves were taken at different rates of electrolyte mixing (Fig. 5).

It can be seen from the Figures 5 and 6 that the speed of the anode and cathode processes increases till $\omega=500 \mathrm{rev} / \mathrm{min}$ and does not change further, which indicates insignificant contribution of the mass transfer rate to the rate of electrochemical processes. On the other hand, the process can be limited by diffusion to a large extent till stirring speed reaches $500 \mathrm{rev} / \mathrm{min}$. 


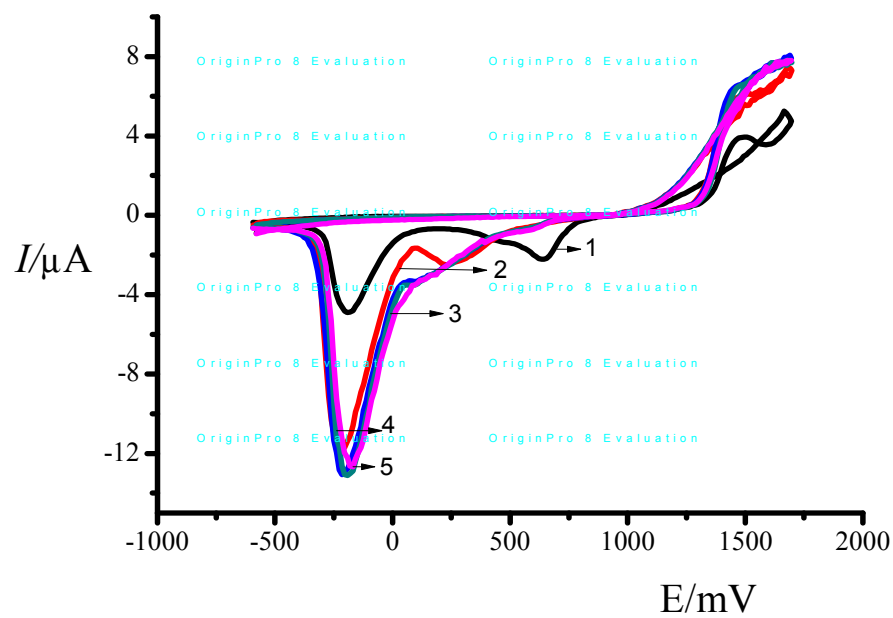

1- $0 \mathrm{rev} / \mathrm{min}, 2-250 \mathrm{rev} / \mathrm{min}, 3-500 \mathrm{rev} / \mathrm{min}, 4-750 \mathrm{rev} / \mathrm{min}, 5-1000 \mathrm{rev} / \mathrm{min}$

Figure 5. Cyclic polarization curves of $\mathrm{Tl}_{2} \mathrm{SO}_{4}$ on the glass carbon electrode at different mixing rates of the solution, $u=20 \mathrm{mV} / \mathrm{s}, \mathrm{c}=10^{-2} \mathrm{~mole} / \mathrm{L}$

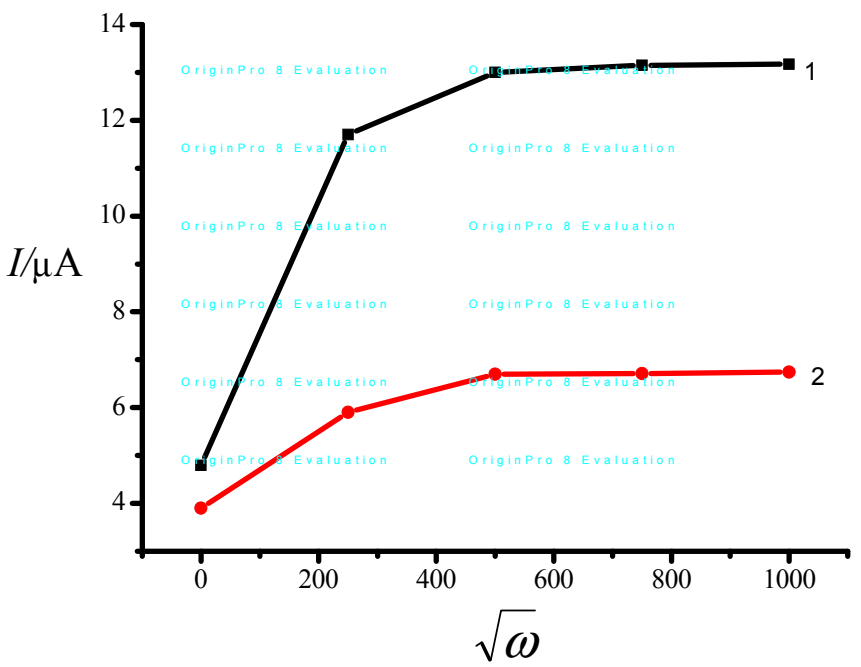

Figure 6. The amperage density dependence of cathode (1) and anode (2) peaks on $\sqrt{ } \omega$, where $\omega$ is the mixing rate $\left(\mathrm{Tl}_{2} \mathrm{SO}_{4}, \mathrm{c}=10^{-2}\right.$ mole/L) 
In order to determine the effect of temperature on the precipitation and dissolution of thallium oxide, cyclic polarization curves were taken at different temperatures, without and with ( $\omega=500 \mathrm{rev} / \mathrm{min}$ ) sweep rate of solution (Fig. 7).

a)

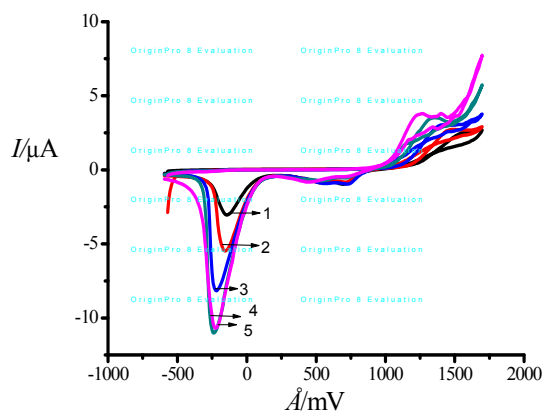

b)

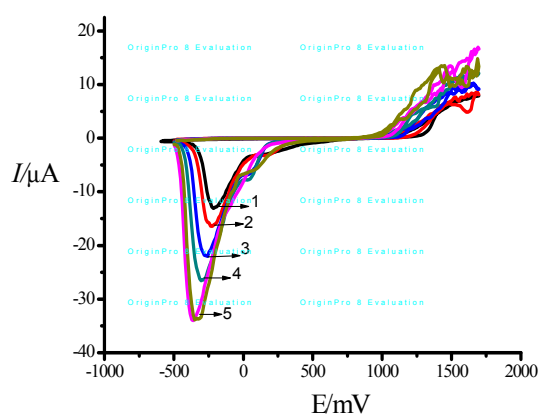

Figure 7. Cyclic polarization curves on the glassy carbon electrode at different temperatures, without sweep rate of solution (a) and $\omega=500 \mathrm{rev} / \mathrm{min}(\mathrm{b})$, $\mathrm{Tl}_{2} \mathrm{SO}_{4}, \mathrm{c}=10^{-2} \mathrm{~mole} / \mathrm{L} . \quad 1-20 ; 2-30,3-40 ; 4-50,5-60{ }^{\circ} \mathrm{C}$

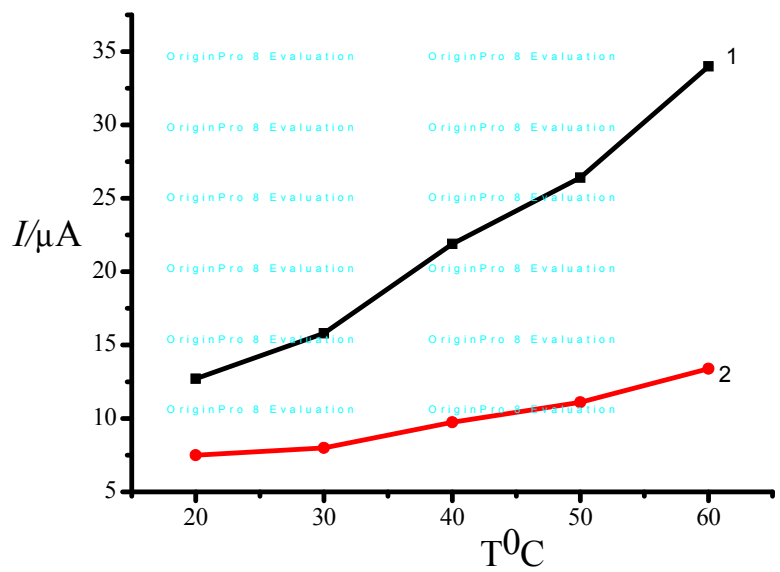

Figure 8. The amperage density dependence of cathode (1) and anode (2) peaks on temperature $\left(\mathrm{Tl}_{2} \mathrm{SO}_{4}, \mathrm{C}=10^{-2} \mathrm{~mole} / \mathrm{L}\right)$ 
Graphs 7 and 8 show that a linear increase of the speed of the cathode and anode processes occurs with the increase of temperature up to $60^{\circ} \mathrm{C}$. Further, the speed maintains the same level and does not change. Therefore, it means that $\omega=500 \mathrm{rev} / \mathrm{min}$ and $\mathrm{T}=60^{\circ} \mathrm{C}$ can be considered as optimal conditions for the precipitation and dissolution of thallium oxide. In Table 2, the activation energies for the cathode and anode process were calculated with and without stirring the electrolyte.

Table 2. The value of activation energy of cathode and anode processes

\begin{tabular}{|c|c|c|c|c|}
\hline Process & $\mathrm{W}, \mathrm{rev} / \mathrm{min}$ & $\begin{array}{c}\text { Number of } \\
\text { points }\end{array}$ & $\begin{array}{c}\text { Correlation } \\
\text { coefficient }\end{array}$ & $\mathrm{E}_{\mathrm{a}}, \mathrm{kJ} / \mathrm{mole}$ \\
\hline cathode & 0 & 5 & 0,90 & $11,7 \pm 0,13$ \\
\hline anode & 0 & 5 & 0,97 & $33,4 \pm 0,35$ \\
\hline cathode & 500 & 5 & 0,99 & $6,5 \pm 0,08$ \\
\hline anode & 500 & 5 & 0,97 & $11,8 \pm 0,13$ \\
\hline
\end{tabular}

The values of the activation energies lead to the following conclusions: the anode process of thallium oxide precipitation is limited by the rate of supply of the $\mathrm{TI}^{+}$ion to the electrode surface. It is also evident that with stirring, the activation energy increases, indicating the transition to the internal-diffusion region of the precipitation process. It means that the process is limited by the rate of charge transfer through the film formed by $\mathrm{Tl}_{2} \mathrm{O}_{3}$.

The anode process, even without stirring the electrolyte, is characterized by a high activation energy. At electrolyte mixing rates equal to $500 \mathrm{rpm}$, the activation energy significantly reduces. This can be explained by the fact that without mixing, the process of dissolution of $\mathrm{Tl}_{2} \mathrm{O}_{3}$ is limited by mixed-diffusion kinetics: the thallium transfer process through the oxide film and the $\mathrm{TI}^{+}$withdrawal process from the electrode surface to the solution volume. When the solution is stirred, the cathode process is limited by the rate of charge transfer through the oxide film.

It is also found that with the increase of temperature, the formation of trivalent thallium intensifies, which can lead to acceleration of the formation of thallium oxide in the anode's space:

$$
2 \mathrm{TI}^{+}+3 \mathrm{H}_{2} \mathrm{O}=\mathrm{TI}_{2} \mathrm{O}_{3}+6 \mathrm{H}^{+}+4 \mathrm{e}^{-}
$$




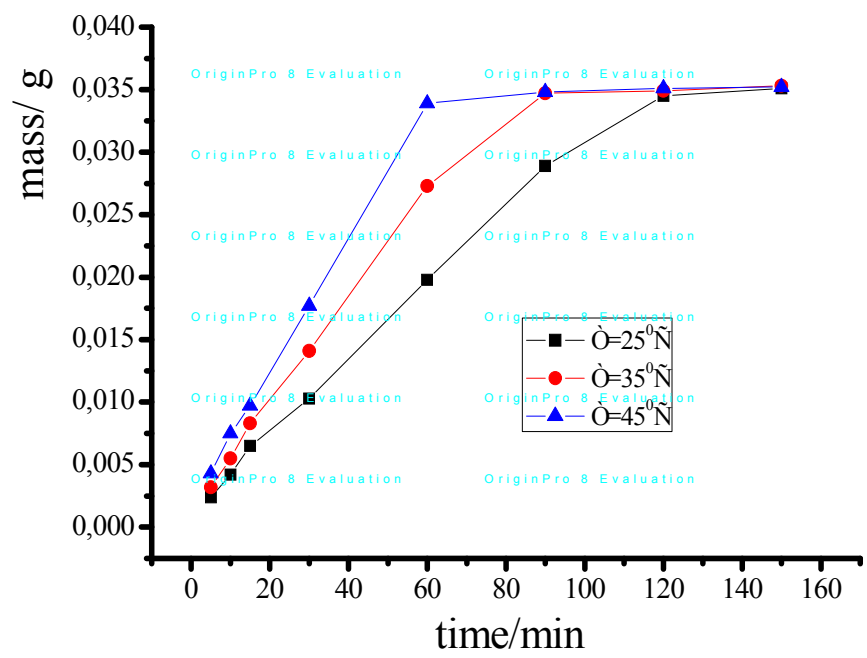

Figure 9. The deposited thallium oxide(III) mass dependence on time at different temperatures

To confirm this fact, the oxide of thallium(III) was deposited on the anode at different temperatures and at various times. The results are shown in Fig. 9. It can be observed that the increase of temperature contributes to achievement of a constant mass of oxide at lower electrolysis time. From the obtained data, values of the rate and activation energy of the electrodeposition processes of $\mathrm{Tl}_{2} \mathrm{O}_{3}$, were calculated.

\section{CONCLUSIONS}

Thereby, there has been established that intermediate products are formed when $\mathrm{Tl}_{2} \mathrm{O}_{3}$ precipitates, presumably: $\mathrm{TIOH}^{2+}, \mathrm{Tl}(\mathrm{OH})_{2}{ }^{+}$. However, over time they transfer into $\mathrm{Tl}_{2} \mathrm{O}_{3}$, which should allow complete dissolution of obtained thallium oxide at potential values equal to $-0.17 \mathrm{~V}$. It has been established that the process of dissolution of thallium(III) oxide is a two-step process, the optimal background electrolyte is $1 \mathrm{~mole} / \mathrm{L} \mathrm{Na}_{2} \mathrm{SO}_{4}$, the optimum $\mathrm{pH}$ value is $11, \omega=500 \mathrm{rev} / \mathrm{min}$ and $\mathrm{T}=60^{\circ} \mathrm{C}$. The results of the work indicate the possibility of selective precipitation of thallium via anode precipitation of $\mathrm{TI}_{2} \mathrm{O}_{3}$. The obtaining thallium can be used for further purification, in particular by zone melting. It is known that the purer the metal enters for refining by the zone melting method, the higher the degree of its purity. High-purity rare metals, in particular thallium, are used in semiconductor technology. 


\section{ACKNOWLEDGMENTS}

The work was carried out within the framework of the program "Fundamental Foundations of Processes Based on Electrochemical Transformations", on the topic "Physicochemical regularities of cathode and anode processes in systems involving thallium".

\section{EXPERIMENTAL}

\section{Materials and methods}

Electrochemical measurements were performed on an AUTOLAB-30 potentiostat - galvanostat with a computer control station in its potentiostatic mode, in 0.01 mole/L $\mathrm{Tl}_{2} \mathrm{SO}_{4}$ solutions. The background electrolyte was of 0.5 mole/ $\mathrm{L} \mathrm{Na}_{2} \mathrm{SO}_{4}$. The area of the working electrode was $1 \mathrm{~cm}^{2}$, platinum was used as an auxiliary electrode, and a silver chloride electrode served as reference. Preparation of electrodes was carried out by mechanical and chemical cleaning.

Mechanical treatment was carried out in order to remove visible contaminants. Chemical cleaning contributed to the dissolution of various compounds from the electrodes' surface. Concentrated solution of nitric acid $\left(\mathrm{HNO}_{3}\right)$ was used for this. Nitrate, sulfate, and sodium acetate were used as background electrolytes. Cyclic polarization curves were obtained in the temperature range of $20-60^{\circ} \mathrm{C}$ and at potential sweep rates of $5-50 \mathrm{mV} / \mathrm{s}$.

In order to establish the limiting stage of the electrochemical process, experiments were carried out at solution stirring rates equal to $0-1000$ $\mathrm{rev} / \mathrm{min}$. All quantitative measurements were carried out in at least three replicates and processed statistically. Electrochemical calculations were performed by using Microcal Origin 8. Quantitative analysis of the composition of the precipitates was carried out by using an ICP OES 8000 optical emission spectrometer (Perkin Elmer) with the WinLab 5 software.

\section{REFERENCES}

1. Korovina S.S Rare and Scattered elements. Chemistry and technology. V. 1. M: MISiS, 1996, 375 (in Russian).

2. Zelikman A.N., Korshunov B.G. Metallurgy of rare metals: textbook for high school. $-2^{\text {nd }}$ edition, elaboration and edition - M.: Metallurgy, 1991, 432 (in Russian). 
3. Bolshakov K.A. Chemistry and technology of rare and scattered elements. M.: High school, 1976, 1, 295 (in Russian).

4. Maher J.P. Aluminium, gallium, indium, and thallium // Annu. Rep. Prog. Chem., Sect. A, 2003, 99, 43-62.

5. Busev A.I., Tipzova V.G. Analytic chemistry of thallium. Success of chemistry. - M: Nauka, 1960, 29, 8, 1011.

6. Kuketaev T. A. Optic and nuclear properties of KDP, activated by thallium ions // Khabarshy (Herald), 2008, 69(in Russian)

7. Damaskin B.B., Petry O.A., Zirlina G.A. Electrochemistry. -2 ed., edited and added - M.: Chemistry, Kolos, 2006, 672 (in Russian).

8. Ussipbekova Ye. Zh., Seilkhanova G.A., Scholz F., Kurbatov A.P., Berezovskiy A.V., Nauryzbaev M.K. Electrochemical refining of thallium in the neutral space// News NAN RK.Chemical Serias. № 5 (407), 2014, 64 - 69 (in Russian).

9. Eremin V.V., Kargov S.I., Uspenskaya I.A., Kuzmenko N.E., Lunin V.V. The basis of physical chemistry. Theory and problems. - M.: Exam, 2005, 480 (in Russian).

10. Gorbachev S.V. Influences of temperature on electrolysis, as kinetic research methods of the nature of electrochemical processes//the $4^{\text {th }}$ session on electrochemistry. Collection of scientific papers - M.: AN USSP, 1959, 61-71 (in Russian).

11. Keshe G. Corrosian of metals. Physic-chemical principles and relevant problems // M. : Metallurgy, 2004, 400 (in Russian).

12. Seilkhanova G.A., Ussipbekova Ye.Zh., Jeyabhrathi Ch., Scholz F., Kurbatov A.P., Nauryzbaev M.K., Berezovskiy A.V. Electrochemical deposition and dissolution of thallium from sulfate solutions // Internatoinal journal of analytical chemistry. vol. 2015, doi:10.1155/2015/357514.

13. Zirlina G.A. Electro catalysis via thallium oxide anodes // Electrochemistry. 1995, 31, 2, 219-221 (in Russian).

14. Utility patent model № 1514 Electrochemical methods of obtaining pure thallium, authors Seilkhanova G.A., Kurbatov A.P., Nauryzbaev M.K., Ussipbekova Ye.Zh., Berezovskiy A.V., Uteshova A.A. - published. 30.06.2016; Bulletin. - № 66 (in Russian).

15. Seilkhanova G.A., Kurbatov A.P., Ussipbekova Ye.Zh., Berezovskiy A.V., Elechtrochemical behavior of thallium in various elecrtrolytes // "KazNU herald" Chemical serials, 2014, 2, 41 - 48 (in Russian). 